\title{
Documentation framework for healthcare simulation quality improvement activities
}

\author{
Melanie Barlow ${ }^{1 *}$ (D), Robyn Dickie ${ }^{1}$, Catherine Morse ${ }^{2}$, Donna Bonney ${ }^{1}$ and Robert Simon ${ }^{2}$
}

Keywords: Quality improvement, Latent errors, Latent threats, In situ simulation, Systems testing, Facility testing, Plan-do-study-act, Healthcare failure mode effects analysis, Point of care

\section{Introduction}

Medical simulation methodology is increasingly being utilised beyond the traditions of education to evaluate patient care workflows, processes, and systems within the health context. A literature review of healthcare facility testing showed that individual clinical departments and singular patient flow processes had been tested under a variety of simulated conditions, such as virtual environments, table top exercises, and live simulation exercises. Each method demonstrated strengths and weaknesses in finding active or latent system failures [1-4]. With the building of our new healthcare facility, it was decided that live (physical) testing of the environment using a medical simulation methodology was the best approach to bridge the gap from architectural plans, to real-world efficient and effective patient care, and for orientation and training of teams to their new environment [4-7]. Although the hospital had yet to open, testing the systems under immersive simulated conditions at the point of care delivery effectively replicated real-world workflows and systems $[1,6]$. Within Australia, two new hospitals reported using medical simulation to test specific clinical scenarios and patient flow journeys prior to service delivery. Unfortunately in both instances, testing beyond the first round did not occur due to funding and human resource limitations. This led to considerable staff workarounds, rectification of process errors after commencement of patient care, and unfavourable media reports $[8,9]$.

This paper will provide an example of an approach to identify latent system issues using live medical simulation and the development of an associated documentation framework. The documentation framework aims to help structure medical simulation scenarios specifically designed

\footnotetext{
* Correspondence: melanie.barlow@mater.org.au

${ }^{1}$ Mater Education Ltd, Queenslane, Brisbane, Australia

Full list of author information is available at the end of the article
}

for quality improvement activities, and to capture and report findings of system deficits identified in the simulations, to key decision-makers.

Our metropolitan mixed public and private healthcare organisation built a satellite health service outside the capital city specialising in day oncology and day surgery, with 64 short stay surgical and medical inpatient beds. Two significant dilemmas were apparent: over half of the staff were new to the main organisation and no onsite critical care support was available. Additionally, the new facility was adapting existing processes from the main central facility, where services were not similar. A serious potential risk to patient safety was noted. Organisational priorities for opening included efficient and effective staff training and systems designed to ensure patient safety in concert with excellent patient experience. Testing of a whole healthcare facility is a large undertaking. It was decided that testing needed to occur over multiple iterations, allowing for system improvements to be made and retested. The final testing cycle was a 24-h live simulation activity. A critical part of the activity was data collection, which led to the development and utilisation of two new tools: the Simulation-based Quality Improvement Tool (SQIOT) and the Healthcare Failure Modes Effects Analysis (HFMEA) Summary Report.

The first reporting tool, SQIOT, utilised the Plan-DoStudy-Act (PDSA) methodology [10-12] as the scenario template to capture data arising from each simulation activity. A second tool, 'HFMEA Report Summary', was underpinned by the Healthcare Failure Modes Effect Analysis (HFMEA) framework [13, 14]. The HFMEA framework provided a way to collate the data and to target summary data to accountable leaders. The combination of the PDSA and HFMEA frameworks as developed and described in this article is a previously unidentified strategy in the literature. The overall design of the simulation 
activity and individual scenarios are outside the scope of this paper. Table 1 outlines the life cycle of the project. Following Table 1 is a detailed description of each phase of the respective tool development.

\section{Simulation activity Phase 1: planning and preparation Objectives:}

1. Identify existing documentation tools designed to test healthcare systems and workflows using live simulation methodology

2. Identify existing documentation tools designed to report outcomes of the systems and workflow simulations to key stakeholders

3. Design appropriate in situ simulation scenarios to test systems and workflows

The predominant determinant for operational readiness was patient and staff safety. This was due to the many interdependencies between the physical environment, the processes, and the people (human factors) [15]. It was identified early that accurate and easy-to-use documentation tools to capture the identified concerns was an essential element of the project. A review of the literature did not reveal previously used documentation tools in healthcare to support facility and system quality improvement activities. It was decided that the team needed to devise its own tools for simulation delivery, data collection and data collation. As many of the patient flow processes were still in draft form at the time of initial testing, it was anticipated that there would be a significant number of observed gaps in the processes and a number of clinical concerns raised by end users during the systems and workflow tests. The Mater Education Simulation Team (MEST) led the execution of this large-scale medical simulation test. Three questions that the MEST aimed to address were:

1. How to document the simulations as a system and workflow test in comparison to traditional educational simulations?

2. What would be the best method to collect and collate the large data sets in the context of concurrent, iterative simulations?

3. In what format should the data be presented to the organisation's decision-makers to ensure that staff would be prepared and oriented, and that the systems and processes are safe?

The Plan-Do-Study-Act (PDSA) methodology provides a structure for cyclical or iterative testing of changes to a system or process, to improve quality and effectiveness [11, 16-18], and therefore ideally suited the iterative nature of our activity. There was little in the literature about using the PDSA framework for quality improvement within medical simulation $[6,7,19,20]$, and there was no evidence of a standard template for running medical simulation scenarios specifically to test clinical and non-clinical processes. As a result, the MEST developed the SQIOT.

Table 1 Four phases of implementation over the life cycle of the project

\begin{tabular}{|c|c|c|}
\hline Phases/location & Date 2015 & Actions \\
\hline $\begin{array}{l}\text { Phase } 1 \\
\text { Planning and preparation } \\
\text { Simulation centre }\end{array}$ & May-Sept. & $\begin{array}{l}\text { a) SQIOT drafted as scenario template and for data collection during iterative simulations } \\
\text { b) HFMEA Report Summary drafted to present collated and risk-rated data from the } \\
\text { simulations to decision-makers. } \\
\text { c) Scenario development and instrument testing undertaken within the simulation centre: } \\
\text { face validity. } \\
\text { Key action Phase 1: testing of documentation tools and scenarios within the simulation centre }\end{array}$ \\
\hline $\begin{array}{l}\text { Phase } 2 \\
\text { Simulation testing } \\
\text { In situ }\end{array}$ & Oct. 6,7 & $\begin{array}{l}\text { Test 1: 'In-hospital' simulation testing of systems and workflows with hospital leaders and } \\
\text { senior clinicians. } \\
\text { Identification of required amendments to systems and workflows. Scenarios refined based } \\
\text { on revised processes. } \\
\text { Test 2: 'In-hospital' simulation testing of systems and workflows with hospital leaders and } \\
\text { senior clinicians repeated. } \\
\text { Identification of further required amendments to systems and workflows. } \\
\text { Scenarios refined based on revised processes for Phase } 3 \text {. } \\
\text { Key action Phase 2: Testing of documentation tools, scenarios and processes/systems/workflows } \\
\text { within the hospital. }\end{array}$ \\
\hline $\begin{array}{l}\text { Phase } 3 \\
\text { Simulation testing } \\
\text { In situ }\end{array}$ & Oct. 22 & $\begin{array}{l}\text { '24-h' simulation in situ simulation testing with hospital staff and simulated patients. } \\
\text { Key action Phase } 3 \text { : testing of processes/systems/workflows within the hospital over a } \\
\text { consecutive } 24-\mathrm{h} \text { period. }\end{array}$ \\
\hline $\begin{array}{l}\text { Phase } 4 \\
\text { In situ }\end{array}$ & Oct. 23 & $\begin{array}{l}\text { 'Post-simulation' staff survey conducted by hospital leadership: 100\% ( } n=112 \text { ) } \\
\text { participating staff confident to open hospital. } \\
\text { Report Summary (HFMEA) submitted: Phases } 2 \text { and } 3 \text { data highlighting } \\
\text { improvements made and further recommendations for refinements to processes } \\
\text { and workflows. Hospital opened with commencement of full service delivery. }\end{array}$ \\
\hline
\end{tabular}




\section{Simulation-based Quality Improvement Observation Tool (SQIOT) Design}

Usually, PDSA Quality Improvement (QI) activities evaluate existing clinical processes when a process change has been implemented and needs to be assessed. The PDSA process aims to identify a distinct relationship between an intentional change in a process, and any variation (positive or negative), to the intended outcome [16]. A complexity with this activity was that the majority of existing procedures, patient flow, staff workflow, and emergency response processes were new and untested. This meant that the more focused use of the PDSA methodology could not be utilised. Instead, each process or system was initially assessed as a whole, with all strengths and weaknesses documented, and system amendments then made for the subsequent testing cycles. The benefit of the PDSA methodology was that it provided the required flexibility for testing within this context $[10,11]$.

The required data to be captured included identified hazards, latent failures, concerns surrounding the patient experience, and suggested quality improvements; most of which could not be pre-identified with specificity. The SQIOT design offered a template that focused on system integrity and quality improvement. It allowed data to be captured from different sources, at different intervals and via different methods, such as direct observations and postsimulation debriefings. The debriefs occurred after every simulation scenario, in each phase (Phases 1-3), and included participating staff, observers, external providers, and simulated patients. Trained simulation faculty facilitated the debriefings. Additionally, a large debrief occurred in Phase 4 with all staff, external providers, and simulated patients who were present at the conclusion of the 24-h simulation event. The SQIOT was organised using the PDSA methodology. Each section is displayed in Fig. 1 and described.

\section{Plan}

The 'Plan' component in the template was divided into a number of elements. The front pages were derived from the organisations' simulation scenario template. It outlined simulation objectives; key scenario information orientating people to time, place, situation, and alignment to organisational strategy; and national safety standards [21]. The larger corporate organisation's five strategic priorities for its business were Safety, Efficiency, Future, Quality, and Experience [22]. Alignment with the organisational strategy was essential for leadership engagement, support in the form of human and financial resourcing, and their commitment to support the required actions when failures were identified. Additionally, alignment to the Australian National Safety and Health Quality Service Standards (NSHQSS) [21] assisted the organisation in the attainment of robust evidence for hospital accreditation. The 'Plan Phase' within the tool documented each step of a drafted individual process or workflow, which acted as the basis for scenario script.
Do

The 'Do' component was the execution of the simulation activity, wherein the observers of the simulation identified if a specific step in the process was or was not achieved by circling 'yes' or 'no'. Data was also captured through free text including refinements required to the simulation. Data was collected in real time, with observers following the simulated process and workflow being tested; video review was not used.

\section{Study}

The 'Study' component of the method allowed data to be captured from multiple sources and formats, both qualitative and quantitative in nature. This enabled precise recognition of system failure, at what point it occurred in the process, and often captured possible solutions to the identified error. Qualitative data included direct observation of the process testing, staff experience within the simulated process/workflow, and participant and simulated patient feedback during the debrief. Comparison studies of actual events to the written processes/workflows and to their anticipated outcomes occurred throughout the activity. Examples of quantitative data collected included emergency team response times, amount of time between unexpected patient presentation at the reception desk to ambulance arrival, and the length of time for ambulance transport from the regional hospital to the central health service.

\section{Act}

The Act' component of the PDSA framework is absent from the form because the identified actions were represented through the 'HFMEA Summary Report' document. The Plan, Do, Study, (Act) components of the PDSA framework informed the execution and iterative nature of the study. Figure 2 shows all the four phases of implementation and alignment of reporting structure.

\section{Simulation activity Phases 2 and 3: simulation-based quality improvement tool \\ Objectives:}

1. Conduct the simulations

2. Utilise and revise the SQIOT

3. Collate and rate risks derived from collected data using the HFMEA Summary Report

4. Report results to organisational decision-makers

Phase 2 testing employed two large-scale iterations, with each iteration being 2 days in duration. Over the two iterations (4 days), a total of 13 simulations were undertaken, as outlined in Table 1. Simulations included unexpected emergency presentations to the front desk, ward-based emergencies, patient discharge processes, administration and housekeeping processes, and general patient care 


\begin{tabular}{|c|c|c|}
\hline & & PDSA Reporting Framework \\
\hline Scenario Title & Process being tested & \\
\hline Date Conducted & Time Conducted & Observer Identification Number \\
\hline
\end{tabular}

Please align the activities learning objectives to the following standards/Criteria (not all standards or principles should be addressed in each activity)

\begin{tabular}{|l|l|l|l|}
\hline \multicolumn{2}{|l|}{ NSQHSS: Standards 1-10 (please circle) } & $\begin{array}{l}\text { Mater } 5 \text { Star } \\
\text { (please circle) }\end{array}$ & Scenario Specific \\
\hline S1 & Governance for safety \& quality & Safety & 1. \\
\hline S2 & Partnering with consumers & Efficiency & 2. \\
\hline S3 & $\begin{array}{l}\text { Preventing and controlling health care } \\
\text { associated Infections }\end{array}$ & Experience & 3. \\
\hline S4 & Medication safety & Quality & 4. \\
\hline S5 & Patient identification \& procedure matching & Sustainability & \\
\hline S6 & Clinical Handover: SHARED & & \\
\hline S7 & Blood \& blood products & & \\
\hline S8 & Pressure injury prevention (PIP) injuries & & \\
\hline S9 & Recognising and responding to the & & \\
\hline S10 & Prevention of falls \& harm from falls & & \\
\hline
\end{tabular}

\begin{tabular}{|c|c|c|c|c|c|}
\hline \multicolumn{4}{|l|}{ Plan } & \multirow{2}{*}{$\begin{array}{l}\text { Do } \\
\text { - Observe Simulation } \\
\text { - Data Analysis }\end{array}$} & \multirow{2}{*}{$\begin{array}{l}\text { Study } \\
\text { - Compare data to your } \\
\text { predictions } \\
\text { - Debriefing data analysis } \\
\text { - What? Why? How? When? }\end{array}$} \\
\hline Predicted Outcomes & \multicolumn{3}{|c|}{$\begin{array}{l}\text { Achieved/Not } \\
\text { Achieved } \\
\text { (please circle) }\end{array}$} & & \\
\hline \multicolumn{6}{|c|}{ 1. Phase one of the simulation } \\
\hline 1.1 & Yes & No & N/A & & \\
\hline 1.2 & Yes & No & N/A & & \\
\hline 1.3 & Yes & No & N/A & & \\
\hline \multicolumn{6}{|c|}{ 2. Phase two of the simulation } \\
\hline 2.1 & Yes & No & N/A & & \\
\hline 2.2 & Yes & No & N/A & & \\
\hline 2.3 & Yes & No & N/A & & \\
\hline \multicolumn{6}{|c|}{ 3. Phase three of the simulation } \\
\hline 3.1 & Yes & No & $\mathrm{N} / \mathrm{A}$ & & \\
\hline 3.2 & Yes & No & N/A & & \\
\hline 3.3 & Yes & No & N/A & & \\
\hline
\end{tabular}

Fig. 1 Sample section from the final version of SQIOT (pages 1-2 of the form)

scenarios. The organisation's leadership team were the participants and observers throughout Phase 2 and comprised of senior executives and clinical leaders $(n=14)$. During this phase, changes were made to the systems and workflows as a result of the simulations. Processes and the simulation scenarios were amended and refined. Any concerns or inefficiencies identified with the SQIOT were also reviewed. The overarching project utilised a participatory action-research model [23] that allowed the SQIOT form to be reviewed and refined between iterations of testing. Key improvements to the tool are outlined in Table 2.
Phase 3, an intense 24-h event, occurred 3 weeks after Phase 2 and involved hospital staff from every service and department rostered over three shifts. Phase 3 consisted of 24 simulations, with trained community members participating as simulated patients $(n=12)$, hospital staff $(n=70)$, third party providers $(n=14)$ (e.g. ambulance, fire services, funeral directors), and MEST members $(n=7)$. All systems and departments operated in synchrony under live simulated conditions with both mannequin-based and simulated patient scenarios. Hospital staff were surveyed after each simulation activity via 


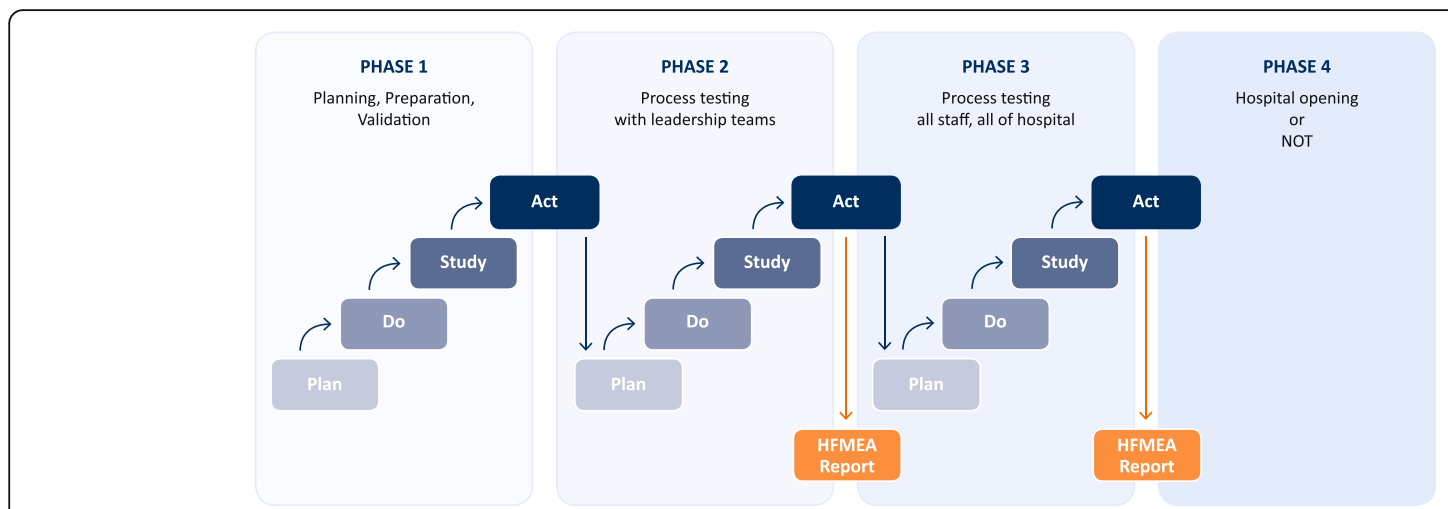

Fig. 2 Phases of the simulation testing and the timing of the PDS(A) and HFMEA reports

a validated tool to ascertain their confidence level in the system/process being tested [24]. At the completion of the $24 \mathrm{~h}$, the hospital leadership, via a staff survey, sought the opinion of the staff on hospital readiness. In Phases 2 and 3 of testing, 67 SQIOT forms were completed.

\section{Simulation activity Phases 2 and 3: HFMEA Summary Report (Act)}

The MEST responsibility was to test systems, analyse data, and to report the findings. MEST was not mandated to take accountability for identified concerns or to be accountable for rectifying system deficits. It was the responsibility of organisational leaders to call to action appropriate people or services, to address the identified concerns. This required designing an effective reporting tool, the 'HFMEA Summary Report'. An extract can be seen in Fig. 3.

All documented data from each test and phase captured on the SQIOT was collated and presented in a format that highlighted the risks, identified potential system impacts, and allowed for decision-makers to prioritise future actions.
HFMEA is normally used to identify causes and effects of failure modes in systems and processes before a significant event or near miss occurs $[13,14,25,26]$. In this study, the HFMEA was used for simulated patient care activities in the real hospital environment. Health Failure Modes, Effects Analysis, and traditional Failure Mode Effects Analysis provide numerical ranking for the identified failures or risks based on severity and probability $[13,23,25,26]$. Numerical ranking scales vary, e.g.1-16 [13, 14, 26], 1-10 [25], 1-5 [27], or 1-4 [28] typically with 1 being 'no' or 'minor impact' through to the largest number meaning catastrophic harm (e.g. permanent patient harm) $[25,26]$. The methodology permits a specific process to be broken down into its elements and analysed for actual and potential weaknesses or failures within the process or system (failure modes) [13, 26]. Because this study generated a large amount of information, simplification was needed. The solution was (1) the risk ranking scale was comprised of a colour coding system (refer to Fig. 3 for the severity ranking matrix; (2) identified concerns/barriers were organised in accordance with the

Table 2 Changes made to SQIOT during testing

\begin{tabular}{lll}
\hline Amendments made to SQIOT & Phase of testing & Rationale \\
\hline Document design & Phase 1 & The document went through multiple versions upon commencement \\
& & $\begin{array}{l}\text { of simulations within the simulation centre and as the hospital processes } \\
\text { and workflows were being redeveloped and amended. }\end{array}$
\end{tabular}

Section: do number of steps in a process reduced

Section: do addition of 'Not Applicable'
Amended after Phase 2 Test 1

Amended after Phase 2 Test 2

\section{Amended after Phase 2} Test 1
Initially, the SQIOT form was too prescriptive as it outlined every single expected step in a care episode or process. As a result, the 'Do' section of the SQIOT was predominately not completed by observers during Phase 2.

Data collectors expressed confusion when completing the tool because a number of prescribed equipment or processes were not in place. What was needed was an option of 'N/A' (not applicable) in addition to 'Yes or No'.

Observers were a mixture of clinical experts, simulation team members, hospital leaders, service support staff, and the embedded simulated patients. After test one, observers requested additional free text space. The key benefit of adding more open space for comments was that observers could document their view, thus ensuring the process was evaluated from multiple perspectives. Later, during data analysis, it was possible to identify themes from the varied observer groups. 


\begin{tabular}{|c|c|c|c|c|c|c|c|}
\hline Simulated Event & Identified Barriers & Impact & $\begin{array}{l}\text { Severity Ranking } \\
\text { Phase } 2 \text { testing }\end{array}$ & $\begin{array}{l}\text { Severity Ranking } \\
\text { Phase } 3 \text { testing }\end{array}$ & Action required & $\begin{array}{l}\text { Who is } \\
\text { responsible }\end{array}$ & $\begin{array}{l}\text { When to be } \\
\text { completed by }\end{array}$ \\
\hline \multicolumn{8}{|c|}{ Service area being tested: Cancer Care Service - Day oncology unit } \\
\hline $\begin{array}{l}\text { Scenario: } \\
\text { Administration of } \\
\text { chemotherapy in } \\
\text { treatment pods }\end{array}$ & \begin{tabular}{|l} 
Placement of \\
treatment chairs \\
requires chair to \\
run off battery. If \\
chair is plugged \\
into $\mathrm{A} / \mathrm{C}$ power, \\
the electrical \\
cord impedes \\
both patient \\
and clinician \\
pathway causing \\
a significant falls \\
risk and inhibiting \\
workflow \\
\end{tabular} & \begin{tabular}{|l} 
Safety \\
Patient experience \\
Efficiency
\end{tabular} & & & $\begin{array}{l}\text { Approved } \\
\text { modifications to } \\
\text { treatment pod } \\
\text { approved and in } \\
\text { progress }\end{array}$ & $\begin{array}{l}\text { Unit Manager and } \\
\text { Capital Works }\end{array}$ & $\begin{array}{l}\text { Specified } \\
\text { timeframe }\end{array}$ \\
\hline Severity & Colour & \multicolumn{6}{|l|}{ Description } \\
\hline Task failure & Eed & \multicolumn{6}{|c|}{ Failure mode that had an immediate and/or significant impact } \\
\hline Serious problem & Orange & \multicolumn{6}{|c|}{$\begin{array}{l}\text { Parts in the process/system that demonstrated actual or potential failure, and workarounds were required to complete the } \\
\text { task }\end{array}$} \\
\hline Minor hindrance & Yellow & \multicolumn{6}{|c|}{ System deficits that had minimal impact, and were easily tolerated by staff and patients } \\
\hline No problem & Green & \multicolumn{6}{|c|}{ No problem, or failure mode identified } \\
\hline
\end{tabular}

Fig. 3 Sample from HFMEA Summary Report

organisation's five strategic priorities [22]; and (3) each identified failure mode was analysed to identify the likely cause. Once a failure mode was identified and reported, the clinical and non-clinical directors then assigned individual accountability to rectify identified concerns within specified time frames. This report format eased the burden on decision-makers to identify, prioritise action, and apply remedies to failure modes prior to errors reoccurring $[12,25]$.
The Phase 3 report combined both Phases 2 and 3 test results demonstrating where improvements had been made, or not made, with descriptions from each test iteration, i.e. something akin to a longitudinal study. The goal of the longitudinal descriptions was to assist the Commissioning Steering Committee to prioritise what it should and could rectify prior to live service delivery. In Table 3 are a few examples of failure modes identified during the

Table 3 Examples of identified failure modes illustrate actual or potential failure modes

\begin{tabular}{|c|c|c|}
\hline Failure mode (identified barrier) & Impact & Outcome \\
\hline $\begin{array}{l}\text { Position of A/C power cord to cancer care treatment chairs } \\
\text { demonstrated significant falls risk to the patient and staff. } \\
\text { Also inhibitive of efficient staff workflow }\end{array}$ & $\begin{array}{l}\text { Safety } \\
\text { Patient experience } \\
\text { Efficiency }\end{array}$ & $\begin{array}{l}\text { Each treatment pod had additional power point installed } \\
\text { and TV's repositioned in each pod }\end{array}$ \\
\hline $\begin{array}{l}\text { No standing orders for adrenaline administration in an } \\
\text { emergency (no resuscitation team onsite) }\end{array}$ & Safety & $\begin{array}{l}\text { Organisational Resuscitation Committee endorsed standing } \\
\text { orders for the hospital for all registered nurses to administer } \\
\text { adrenaline in a medical emergency }\end{array}$ \\
\hline $\begin{array}{l}\text { Imminent birth presenting to reception (no emergency } \\
\text { department) }\end{array}$ & $\begin{array}{l}\text { Safety } \\
\text { Efficiency }\end{array}$ & $\begin{array}{l}\text { Required equipment purchased and staff orientated to its } \\
\text { location and function }\end{array}$ \\
\hline
\end{tabular}

to another location

No neonatal resuscitation equipment available

Unknown process - unknown if oxytocic medications are/

will be available from pharmacy

Adult (chest pain) and a paediatric (asthma) presenting

to front reception

With one administration staff on front desk, cannot initiate required phone calls at the desk to get help and attend to patient

Insufficient emergency equipment located on reception level of the hospital

Support services assistant and security currently not on medical emergency page (security: external company)

Staff knowledge in management of a paediatric emergency or

first aid measures (no paediatric inpatients for this hospital)

\author{
Safety Recommendations implemented: \\ Efficiency Staff assist button for front reception \\ Patient experience Mobile phone/deck phone at reception \\ External security company to be added \\ to the emergency pager list \\ Emergency equipment purchased for reception: \\ - Oxygen and masks (adult and paediatric) \\ - AED \\ - Vital signs monitor \\ - PPE \\ - IV cannulation \\ Paediatric education plan and resuscitation training \\ planned and commenced
}

Safety

Efficiency
Volume of overhead emergency buzzer in inpatient areas. Staff in single rooms with door closed cannot hear staff assist or code blue call bells 
simulated testing, alignment with organisational strategic priorities, and summary of associated outcomes.

\section{Discussion}

In the literature, there is a paucity of evidence of using PDSA QI as a methodology in healthcare simulation testing alongside HFMEA reporting. The methodology used in this study produced results that satisfied leadership and led to an uneventful opening of the satellite hospital with no patient or staff harm, and a grateful community.

The iterative amendments to the tool throughout Phases 1-3 allowed for continued improvements in data collection. Small changes such as reducing the number of steps documented in a process led to more data being collected and more meaningful data. This improvement was thought to be attributed to (1) reducing cognitive load for the data collectors, (2) better characterising of the 'real-life' processes, and (3) highlighting the salient parts of the process.

Observers were trained how to use the tool, but did not have an opportunity to practice using it in action prior to the commencement of Phase 2, Test 1. It seems likely that data collection would have been strengthened by observer training. Nevertheless, useful data was collected with each iteration and, as might be expected, the data usefulness improved as observers became more experienced, and the instruments designed with flexibility in mind were improved as the multi-phased testing process was implemented.

Although this activity was not testing a single system or process, it required the design of a report that could capture the actual and potential failure modes of multiple individual processes and systems. To do this effectively, the second template (HFMEA Summary Report) was designed. This documentation methodology proved beneficial in two ways. First, it provided organisational decision-maker's precise and actionable information on identified latent failures with sufficient information to make informed decisions based on priorities and resourcing. Second, it served as positive reinforcement for middle management and front line staff that their concerns were being taken seriously by the senior managers and that their suggestions for improvement were acted upon. It reinforced a positive safety culture for which all staff felt empowered and invested in the quality and safety of their new hospital.

Normally, HFMEA identifies the points of failure from a process perspective. This study went a step further through the inclusion of feedback from the simulated patients as their role as consumers. A limitation of testing a system or process under simulated conditions is the validity of 'guessing' or making assumptions about the patient perspective as a recipient of care within that system. To help ameliorate this problem and strengthen the testing of the system and its interdependencies, local consumers who would be using the health service were trained as simulated patients. The simulated patient participated in the associated simulation activity debrief, and their thoughts and opinions were captured. This provided reassurance that a system or process was safe and efficient, while at the same time resulted in a positive patient experience. The idea was to combine safe and reliable processes with a patient-centred approach. Simulation and HFMEA used collaboratively permitted unique and precise prioritising failure modes. Without this comprehensive approach, failure modes might have remained unnoticed or unrecognised $[14,25,29,30]$.

The hospital leadership and Commissioning Steering Committee team realised the value of the simulation activity. This realisation led them to make accurate and well-informed decisions regarding operational readiness. They were so confident in the simulation-based testing process that a delay in the highly publicised opening date was among the possible options. Patient safety and staff preparedness was paramount. The simulation testing and the detailed reporting of the activities added strength to the decision-making of the hospital leadership team and provided reassurance to the hospital executive council, Commissioning Steering Committee, and the hospital board members.

\section{Conclusion}

The simulation methodology utilised for the testing of health systems and processes provides a unique lens through which staff at all levels can observe, assess, and evaluate [1,5-7]. The advantage of simulation as a quality improvement methodology is that one cannot accurately predict system performance without testing prior to 'going live'. While we may intuitively agree with the truth of that statement, we and our health service were extremely pleased to see how much true value was received via the simulation-based testing and the associated methodology provided in this report. Smart, dedicated professionals created the physical layout, thoughtfully designed the systems, and placed highly trained professionals within these designs. The natural motivation of all these professionals was patient and staff safety, system effectiveness, and patient satisfaction. Despite all these talents and dedication, there were still a number of weaknesses and errors, a few of which with a pretty high likelihood of resulting in a costly error remained in the system. The PDSA methodology utilised within this iterative and increasingly complex simulation activity allowed incremental and substantial positive changes to occur. While the process does use a number of resources, it is believed to have resulted in a greater likelihood in producing more positive and widespread sustainable change in the organisation, than 'one off' 
change implementation [10, 31]. This study demonstrated that in this circumstance, an iterative PDSA quality improvement methodology was an effective framework for structuring simulation-based healthcare system testing. The PDSA and HFMEA frameworks collectively allowed rapid data collection regarding individual systems or processes, and a larger ecosystem working in synchrony during a 24-h simulation event. This allowed visibility of the interrelated parts and gaps within the coordination between individuals, departments, and systems.

The validity of the conclusions is fundamentally dependent on the accuracy of the simulation scenarios. The future use of this type of simulation testing needs to include how to portray clinical process authentically enough to elicit appropriate care delivery and staff behaviours and attitudes that would naturally occur during service delivery. In this activity, we believe that the quality of the simulations were sound to start with and got better with each iteration. Scenarios were designed and tested during Phase 1 within the simulation centre. Additionally, the simulations were run four times within the real hospital environment (Phases 2-3) with continuous revalidation of scenario content. Although there were multiple observers of the simulation activities, there may have been interactions or potential system weaknesses missed simply due to observers' natural inability to see and hear all. Consideration for future activities should be capturing video of the simulations to undertake a second review and to enable inter-rater reliability studies of the Observation Simulation Quality Improvement Observation Tool.

The inclusion of feedback and suggestions from frontline staff ultimately led to better processes and less workarounds, as the staff helped to shape and design the system in which they would function. A secondary outcome was that before the doors of the health service opened, there was a positive simulation culture throughout the organisation, and recognition of how simulation methodology can support a health service beyond education and training.

\begin{abstract}
Acknowledgements
The authors of the paper would like to acknowledge Mater Education's contribution, in particular Mater Education's Practice Improvement Centre Simulation Team, Pauline Lyon, Katherine Jackman, education coordinators, and Mater Private Hospital Springfield staff for their support of this project.
\end{abstract}

Funding

Funding for all aspects of this project was provided by the Mater Education.

\section{Availability of data and materials}

The datasets used and analysed during the current study are available from the corresponding author upon reasonable request.

\section{Authors' contributions}

The conception, co-ordination of the study design, analysis of data and writing and preparation of the manuscript was led by MB. RD, CM, DB, and RS contributed to the study design and writing and critical revisions of the manuscript. All authors read and approved the final manuscript.

Ethics approval and consent to participate

The study approval was from Mater Ethics and Governance Committee (HREC/15/MHS/79).

\section{Competing interests}

The authors declare that they have no competing interests.

\section{Publisher's Note}

Springer Nature remains neutral with regard to jurisdictional claims in published maps and institutional affiliations.

\section{Author details}

${ }^{1}$ Mater Education Ltd, Queenslane, Brisbane, Australia. ${ }^{2}$ Center for Medical Simulation, Queenslane, Brisbane, Australia.

Received: 30 April 2017 Accepted: 11 October 2017

Published online: 17 October 2017

\section{References}

1. Alder M, Mobley B, Eppich W, Lappe M, Green M, Mangold K. Use of simulation to test systems and prepare staff for a new hospital transition. J Patient Saf. 2015; doi:https://doi.org/10.1097/PTS.0000000000000184.

2. Kerner R, Gallo K, Cassara M, D'Angelo J, Egan A, Simmons J. Simulation for operational readiness in a new freestanding emergency department. Simul Healthc. 2016; doi:https://doi.org/10.1097/SIH.0000000000000180.

3. Bender J. In situ simulation for systems testing in newly constructed perinatal facilities. Semin Perinatol. 2011; doi:https://doi.org/10.1053/.semperi.2011.01.007.

4. Ventre K, Barry J, Davis D, Baiamonte V, Wentworth A, Pietras M, Coughlin L, Barley G. Using in situ simulation to evaluate operational readiness of a children's hospital-based obstetrics unit. Simul Healthc. 2014;9:102-11.

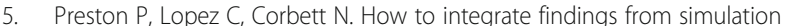
exercises to improve obstetrics care in the institution. Semin Perinatol. 2011; doi:https://doi.org/10.1053/.semperi.2011.01.008.

6. Gardner A, Ahmed R, George R, Frey J. In situ simulation to assess workplace attitudes and effectiveness in a new facility. Simul Healthc. 2013; doi:https://doi.org/10.1097/SIH.0b013e31829f7347.

7. Yager P, Collins C, Blais C, O'Connor K, Donovan P, Martinez M, Cummings B, Hartnick C, Noviski N. Quality improvement utilizing in-situ simulation for a dualhospital pediatric code response team. J Pediatr Otorhinolaryngol. 2016;88:42-6.

8. Queensland Health, Queensland Government. Lady Cilento Children's Hospital review operational and building. 2015. https://publications.qld.gov. au/dataset/lady-cilento-children-s-hospital-commissioning-review/resource/ 2cd8b21c-34eb-4b84-a96a-06454b3cfc6d Licensed under Creative Commons Attribution. Accessed December 2016.

9. Parliament of Western Australia, Perth. More than bricks and mortar: the report of the inquiry into the organisational response within the Department of Health to the challenges associated with commissioning the Fiona Stanley Hospital. Education and Health Standing Committee. 2014; Report 2. Accessed December 2016.

10. Taylor M, McNicholas C, Nicolay C, Darzi A, Bell D, Reed J. Systematic review of the application of the plan-do-study-act method to improve quality in healthcare. BMJ Qual Saf. 2014;23:290-8.

11. Science of improvement: testing changes. Institute for Healthcare Improvement. http://www.ihi.org/resources/Pages/Howtolmprove/ ScienceoflmprovementTestingChanges.aspx. Accessed 4 May 2016.

12. Speroff $T, O^{\prime}$ Connor G. Study designs for PDSA quality improvement research. QMHC. 2004;13:17-32.

13. DeRosier J, Stalhandske E, Bagian JP, Nudell T. Using healthcare failure mode and effect analysis: the VA National Center for patient safety's prospective risk analysis system. Jt Comm J Qual Improv. 2002;28:248-67. 209

14. Nielsen D, Dieckmann P, Mohr M, Mitchell A, Ostergaard D. Augmenting health care failure mode effects analysis with simulation. Simul Healthc. 2014;9:48-55.

15. Birnbach D, Nevo I, Scheinman S, Fitzpatrick M, Shekhter I, Lombard J. Patient safety begins with proper planning: a quantitative method to improve hospital design. Qual Saf Health Care. 2010; doi:https://doi.org/10. 1136/qshc.2008.031013. 
16. Speroff $\mathrm{T}, \mathrm{O}^{\prime}$ Connor G. Study design for PDSA quality improvement research. QMHC. 2004;13:17-32.

17. Deming W. Out of the crisis. Cambridge, MA: Cambridge University Press; 1986.

18. Nakayama D, Bushey T, Hubbard I, Cole D, Brown A, Grant T, Shaker I. Using a plan-do-study-act cycle to introduce a new OR service line. AORN. 2010; https://doi.org/10.1016/j.aorn.2010.01.018.

19. Murphy J. Using plan do study act to transform a simulation center. Clinical Simulation in Nursing. 2013; doi:https://doi.org/10.1016/j.ecns.2012.03.002.

20. Ozekcin L, Tuite P, Willner K, Hravnak M. Early identification of patient physiologic deterioration by acute care nurses. Clin Nurs Spec. 2015:166-73.

21. Australian Commission on Safety and Quality in Health Care, National Safety and Quality Health Service Standards. Sydney; 2012.

22. Exceptional every time strategy document. 2016. http://www.exceptional. org.au/. Accessed December 2016.

23. Cornwall A, Jewkes R. What is participatory research? Soc Sci Med. 2010 Mar; $70(5): 794$

24. Franklin A, Burns P, Lee C. Psychometric testing on the NLN Student Satisfaction and Self-Confidence in Learning, Simulation Design Scale, and Educational Practices Questionnaire using a sample of pre-licensure novice nurses. Nurse Educ Today. 2014; doi:https://doi.org/10.1016/..nedt.2014.06.011.

25. Davis S, Riley W, Gurses A, Miller K, Hansen H. Failure modes and effects analysis based on in-situ simulations: a methodology to improve understanding of risks and failures. 2008. Available at: http://www.ncbi.nlm. nih.gov/books/NBK43662/pdf/advances-davis_60.pdf.Accessed 4 July 2016

26. Ashley L, Dexter R, Marshall F, McKenzie B, Ryan M, Armitage G. Improving the safety of chemotherapy administration: an oncology nurse-led failure mode and effects analysis. Oncol Nurs Forum. 2011;38:e436-44.

27. Spath P. Home study program: using failure mode and effects analysis to improve patient safety. AORN. 2003;78:16-37.

28. Paparella S. Failure modes and effects analysis: a useful tool for risk identification and injury prevention. J Emerg Nursing. 2007; doi: https://doi. org/10.1016/j.jen.2007.03.009

29. Guise J, Mladenovic J. In situ simulation: identification of system issues. Semin Perinatol. 2013; doi: https://doi.org/10.1053/.semperi.2013.02.007.

30. Geis G, Pio B, Pendergrass T, Moyer M, Patterson M. Simulation to assess the safety of new healthcare teams and new facilities. Simul Healthc. 2011; https://doi.org/10.1097/SIH.0b013e3182dff30

31. Donnelly P, Kirk P. Use the PDSA model for effective change management Educ Prim Care 2015; doi:10..1080/14739879.2015.11494356.

\section{Submit your next manuscript to BioMed Central and we will help you at every step:}

- We accept pre-submission inquiries

- Our selector tool helps you to find the most relevant journal

- We provide round the clock customer support

- Convenient online submission

- Thorough peer review

- Inclusion in PubMed and all major indexing services

- Maximum visibility for your research

Submit your manuscript at wuw biomedcentral.com/submit

CBiomed Central 